\title{
DEVELOPMENT AND CHARACTERISATION OF EST-SSR MARKERS FOR GENETIC ANALYSIS OF CASUARINASPECIES
}

\author{
Li $Z^{1}$, Zhang $\mathbf{Y}^{1, *}$, Hu $\mathrm{P}^{2}$, Zhong $\mathrm{CL}^{1}$, Wei $\mathrm{YC}^{1}$, Meng JX $\mathrm{X}^{1}$, Wang $\mathrm{YJ}^{1} \&$ Bush $\mathrm{D}^{3}$ \\ ${ }^{1}$ Research Institute of Tropical Forestry, Chinese Academy of Forestry, Longdong, 510520 Guangzhou, China \\ ${ }^{2}$ Experimental Centre of Forestry in North China, Chinese Academy of Forestry, Beijing 102300, China \\ ${ }^{3}$ CSIRO Australian Tree Seed Centre, GPO Box 1600, Canberra, ACT 2601, Australia \\ *zhangyongritf@caf.ac.cn
}

Submitted August 2020; accepted December 2020

\begin{abstract}
Simple sequence repeats (SSR) markers have greater advantages relative to other molecular markers in genetic analysis due to their Mendelian inheritance and co-dominance expression features. Numerous expressed sequence tags (EST) of genus Casuarina, now available from public databases, make it possible to develop EST-SSR markers with high efficiency at low cost. From the analysis of 12,063 EST derived from casuarinas, 367 SSR loci were identified from 352 unigenes, and the distribution frequency of SSR loci was 3.0\%. The di- and trinucleotide accounted for 57.77 and $34.06 \%$ respectively. They comprised overwhelming majority in five types of repeat motifs of SSR, and AG/CT was the most predominant motif type of SSR. A total of 79 primer pairs were designed based on the non-redundant EST-SSR sequences, but only 21 were successfully amplified and generated polymorphic SSR products in four different Casuarina species and eight clones of C. equisetifolia. Eight primer pairs out of the 21 were applied for paternity analyses of open-pollinated progenies of one female individual of C. equisetifolia. At $95 \%$ confidence interval, 76 male individuals were identified as pollen parents of 262 out of 461 progenies, but at $80 \%$ confidence interval, 84 male individuals were identified as father trees of 328 out of the 461 progenies.
\end{abstract}

Keywords: Mendelian inheritance, cross-species transferability, parentage analysis

\section{INTRODUCTION}

The family Casuarinaceae comprises four genera and 96 species occurring naturally from Australia to the Pacific islands and in South-east Asia (Turnbull 1990). Casuarina are nitrogen-fixing trees of considerable importance in many tropical and subtropical regions of the world. Over 2 million ha have been planted for wood production, shelterbelts, land rehabilitation and for ornamental purposes around the world (Zhong et al. 2011). The most important Casuarina in international plantings are limited to a few species, viz. $C$. equisetifolia, C. cunninghamiana, C. glauca and C. junghuhniana. Due to their important roles in coastal protection, sand dune stabilisation and agroforestry systems, researches on genetic diversity, reproductive biology and breeding system, genetic improvement, and ecological function have been carried out in many countries (Nagarajan et al. 1998, Warren \& Zou 2002, Huang et al. 2009, Broadhurst 2011, Samarakoon et al. 2013, Zhang et al. 2014, Zhang et al. 2016).
Development of molecular marker techniques has provided efficient tools for genetic analyses of plants. Molecular markers such as RAPD (random amplified polymorphic DNA) (Ho et al. 2002), AFLP (amplified fragment length polymorphism) (Gaskin et al. 2009, Huang et al. 2009) and ISSR (inter simple sequence repeat) (Yasodha et al. 2004, Ho \& Lee 2011) have been used for genetic relationship analysis, genetic diversity assessment and hybrid identification in Casuarina. However, all the aforementioned molecular markers are dominant markers with limitations such as difficulty in distinguishing heterozygotes as well as poor transferability and repeatability, making them inadequate for parentage analyses in Casuarina.

Microsatellites, known as simple sequence repeats (SSR), are short (1-6 bp long), tandemly repeated DNA sequences widely dispersed throughout eukaryotic genomes (Powell et al. 1996). The co-dominant microsatellites are robust markers as they are hypervariable and multiallelic, highly reliable, uniformly distributed 
in plant genome, and transportable among closely related species. The positive features of microsatellites make it an efficient tool for genetic diversity assessment, parentage analysis, variety protection, gene mapping and markerassisted selection in plants (Ho et al. 2006, Huang et al. 2016, Lee et al. 2018).

Unlike traditional methods of SSR discovery, new advances in genomic technologies have generated a large number of ESTs (express sequence tags) in many plant species, which contain numerous microsatellite sequences. Exploring and identifying microsatellites from EST is now available in plants, as EST databases become increasingly common in public databases such as EMBL and Genbank. Development of EST-SSR markers through mining EST databases has become a fast, efficient, and low-cost option for many plant species. A large number of ESTs derived from C. equisetifolia and C. glauca are available in the Genbank (Hocher et al. 2006). These sequence data offer a prerequisite for developing EST-SSR markers of plant in the Casuarina genus. Though some EST-SSR markers of Casuarina genus have been developed (Xu et al. 2018), only limited markers are actively employed in casuarina improvement programmes. Developing more highly polymorphic EST-SSR markers is necessary, especially for purposes like parental analysis in Casuarina.

The objectives of this study were: (1) to analyse the frequency and distribution of SSR in EST of Casuarina, (2) to develop and validate EST-SSR markers for polymorphism in Casuarina and assess their cross-species transferability, and (3) to explore their application in parentage analysis of Casuarina progeny seedlings.

\section{MATERIALS AND METHODS}

\section{SSR retrieval and pre-treatment}

EST sequences were downloaded from EST database at the NCBI (National Centre for Biotechnology Information, http://www.ncbi. nlm.nih.gov/) using Casuarina as search keyword. A total of 34,897 EST sequences of C. equisetifolia and C. glauca were obtained for this study. Redundancy EST sequences were aligned by ESTtrimmer software (http://pgrc.ipk-gatersleben. $\mathrm{de} / \mathrm{misa}$ download/esttrimmer.pl) to remove the $5^{\prime}$ or $3^{\prime}$ end of poly A or poly $\mathrm{T}$ stretches within $50 \mathrm{bp}$, and EST sequences less than $100 \mathrm{bp}$ were discarded. After pretreatment, the software SSR Identification Tool (http://archive. gramene.org/db/markers/ssrtool) was used to search for SSR from these EST sequences. The identification criteria were dinucleotide repeats $\geq 9$, trinucleotide $\geq 6$, and tetra- to hexanucleotide $\geq 5$.

Non-redundant EST sequences containing SSR were used to design primers with the software PRIMER 5.0. The parameters were set as follows: GC content $40-60 \%$, annealing temperature $53-57{ }^{\circ} \mathrm{C}$, expected amplified product size 100-500 bp, and primer length 18-24 nucleotides. All primers were synthesised by the Beijing Genomics Institute.

\section{DNA extraction and SSR primer screening}

Genomic DNA of Casuarina for primer screening was extracted from fresh young branchlets of C. equisetifolia clone "A8" using a modified CTAB method (Doyle \& Doyle 1990). PCR amplification system for screening of primers was $10 \mu \mathrm{L}$ in volume, which consisted of $1.0 \times$ buffer $(100 \mathrm{mM}$ Tris- $\mathrm{HCl} \mathrm{pH} 9.0,80 \mathrm{mM}(\mathrm{NH} 4)_{2} \mathrm{SO}_{4}, 100 \mathrm{mM}$ KCl-0.5\% NP-40), 2.0 mM MgCl $2-200 \mu \mathrm{M}$ dNTP, $0.5 \mu \mathrm{M}$ forward primer, $0.5 \mu \mathrm{M}$ reverse primer, 1 U Taq DNA polymerase, and 10-40 ng genomic DNA. The PCR reaction program was: predenaturation at $94{ }^{\circ} \mathrm{C}$ for $5 \mathrm{~min}$, followed by 35 cycles of $94{ }^{\circ} \mathrm{C}$ for $30 \mathrm{~s}, 55^{\circ} \mathrm{C}$ for $30 \mathrm{~s}$, and $72^{\circ} \mathrm{C}$ for $1 \mathrm{~min}$, and finally $72{ }^{\circ} \mathrm{C}$ for an extension of $10 \mathrm{~min}$. PCR products were examined by electrophoresis on a $1.0 \%$ agarose gel stained with 1:20 GoldView in 1× TAE and photographed with Photoprint 215 SD.

\section{EST-SSR polymorphism and cross-species transferability detection}

Primer pairs that produced clear SSR product bands were selected to detect their polymorphism and cross-species transferability using 12 individuals belonging to four species of the genus Casuarina (C. equisetifolia, C. glauca, C. cunninghamiana, C. junghuhniana) and eight clones of C. equisetifolia. The aforementioned PCR reaction system with $10 \mu \mathrm{L}$ in volume was used, and extra $10 \mathrm{pmol}(0.01 \mu \mathrm{L})$ Fluorescent-dUTP was added into the system for SSR genotyping in ABI 3130xl genetic analyser. Touchdown PCR program was employed to the ABI 3130xl genetic analyser. The Touchdown program consisted of 
(1) $94{ }^{\circ} \mathrm{C}$ for $5 \mathrm{~min}, 20$ cycles at $94{ }^{\circ} \mathrm{C}$ for $1 \mathrm{~min}$, $60-50{ }^{\circ} \mathrm{C}$ for $30 \mathrm{~s}$ with a decrease of $0.5{ }^{\circ} \mathrm{C}$ per cycle and $72{ }^{\circ} \mathrm{C}$ for $1 \mathrm{~min}$; (2) 30 cycles of $94^{\circ} \mathrm{C}$ for $30 \mathrm{~s}, 58{ }^{\circ} \mathrm{C}$ for $30 \mathrm{~s}$ and $72{ }^{\circ} \mathrm{C}$ for $1 \mathrm{~min}$; and (3) a final extension at $72{ }^{\circ} \mathrm{C}$ for $10 \mathrm{~min}$. Detection of each SSR was performed on the ABI 3130xl genetic analyser when PCR products were confirmed through agarose gel electrophoresis.

The detection procedure followed the standard module using software GeneMapper 4.0, and each allele and its fluorescence intensity (units) were verified by visual inspection. In order to verify the existence of sequence repeat variation in SSR locus among different clones of Casuarina, some PCR products were recovered for sequencing using the ABI PRISM 3730 sequencing equipment at the Beijing Genomics Institute.

\section{Paternity analyses of open-pollinated progenies of $C$. equisetifolia}

To carry out paternity analysis of open-pollinated progenies of a female individual using the newdeveloped SSR markers, a dominant female individual in a 5-year-old provenance test plantation of C. equisetifolia was selected, and its open-pollinated seeds were collected. This provenance test plantation is surrounded by evenaged mixed plantations of Acacia auriculiformis and C. equisetifolia. Young branchlets of the selected female and 169 male trees which could be the potential pollen donors (father trees) were sampled and dried on silica gel in the field and then transferred to an ultra-low temperature freezer for storage prior to DNA extraction. The open-pollinated seeds were sown in a tray and kept in a greenhouse for germination and seedling growth.

Genomic DNA of 461 progeny seedlings, one mother tree and the 169 potential father trees was extracted from young branchlets using modified CTAB method mentioned above. Eight SSR primer pairs (EST-C01 to EST-C08) with relatively high polymorphism were used to genotype the 631 individuals. A likelihood-based paternity analysis approach was applied to the 461 progenies based on multilocus genotypes for progenies, potential fathers and mother using CERVUS Version 3.0 (Kalinowski et al. 2007). Two confidence intervals of 95 and $80 \%$ were set for determination of the most likely father by parentage analyses using CERVUS 3.0 software.
In this study, the simulation parameters required by the program were set as follows: 10,000 cycles, 169 candidate father individuals, 0.90 and 0.01 as the proportions of loci typed and mistyped respectively.

\section{RESULTS}

\section{Characterisation of frequency and distribution of SSR in EST sequences}

A total of 12,063 unigenes (non-redundant sequences) were obtained after alignment of redundant EST sequences using EST-trimmer software. Within these unigenes, 367 SSR loci were identified from 352 unigenes containing SSRs. There were five types of repeat motifs in the 367 SSR loci, namely, di-, tri-, tetra-, pentaand hexanucleotide repeat motifs (Figure 1). This result suggested that only $2.9 \%$ unigenes contained SSRs, which represented an average density of one SSR in every $19.83 \mathrm{~kb}$. Of the five types of motifs, di-and trinucleotide presented an overwhelming majority, accounting for 57.77 and $34.06 \%$ respectively. By contrast, the remaining three kinds of repeat motifs (tetra-, penta- and hexanucleotide) only accounted for 3.27, 0.82 and $3.54 \%$ respectively.

In view of their overwhelming majority, only di- and trinucleotide motifs were used for analysis of motif type. As shown in Table 1, within 212 dinucleotide motifs, the motif AG/CT had the highest frequency of $93.87 \%$, followed by motifs $\mathrm{AT} / \mathrm{TA}(3.30 \%)$ and AC/TG $(2.83 \%)$. Of the 127 trinucleotide motifs, AAG/TTG was the most abundant, with a frequency of $44.09 \%$, followed by the AGT/TCA (11.02\%), AGT/ TCA (10.24\%), ACC/TGG (7.87\%), ACG/ TGC $(7.09 \%)$, AAC/TTG and AAC/TTG (both $5.51 \%$ ), and AAT/TTA and ACT/TGA (both $3.94 \%)$. The motif CCG/GGC $(0.79 \%)$ had the lowest frequency in all trinucleotide motifs.

\section{Development of EST-SSR markers}

Thirty-two of 79 primer pairs designed for Casuarina were amplified and generated clear SSR products in $1.0 \%$ agarose gel under the given PCR system and reaction conditions. The remaining 47 primer pairs either had no amplified product or produced a number of faint bands indicative of non-specific SSR amplified products and were discarded. 


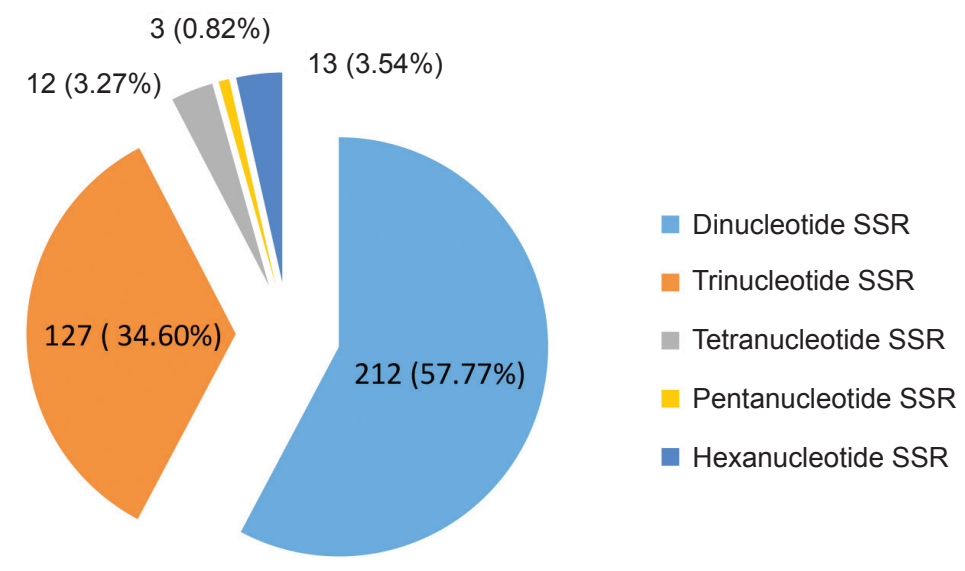

Figure 1 Frequency distribution of five types of SSRs in 367 SSR loci within 352 EST sequences; numbers outside brackets are the SSR numbers identified from 367 SSR loci and numbers between brackets are their percentages

Table 1 Types and proportions of repeat motifs in two kinds of SSRs obtained from Casuarina ESTs

\begin{tabular}{lccc}
\hline SSR type & Type of repeat motif & No. of SSR & Proportion $(\%)$ \\
\hline AG/TC & 199 & 93.87 \\
Dinucleotide & AT/TA & 7 & 3.30 \\
AC/TG & 6 & 2.83 \\
Overall & 212 & 100.00 \\
\hline AAG/TTC & 56 & 44.09 \\
AAT/TTA & 5 & 3.94 \\
AAC/TTG & 7 & 5.51 \\
ACG/TGG & 10 & 7.87 \\
AAC/TTG & 7 & 5.51 \\
ACT/TGA & 5 & 3.94 \\
CCG/GGG & 1 & 0.79 \\
AGT/TCA & 14 & 11.02 \\
AGT/TCA & 13 & 10.24 \\
ACG/TGC & 9 & 7.09 \\
Overall & 127 & 100.00 \\
\hline
\end{tabular}

The 32 primer pairs were further examined by amplifying the SSR loci in genomic DNA of eight clones of C. equisetifolia and four Casuarina species, aimed at detecting polymorphism among different cultivars (clones) and cross-species transferability. In total, 21 primer pairs were found to present polymorphism among eight clones and fours species, and all 21 performed excellent cross-species transferability within Casuarina genus based on successful amplification with polymorphic loci. The characterisations of 21 primer pairs based on 12 individuals are shown in Table 2.
According to genotyping results for eight clones of C. equisetifolia and four Casuarina species, the number of alleles per locus ranged from 3 to 5 , and in total 38 alleles were found for the 12 individuals. Allelic profiles of the 12 individuals genotyped by the first 10 SSR loci are presented in Table 3.

PCR products amplified by primer pair EST-C10 from different clones were recovered and sequenced, and the four DNA fragment sequences containing variable simple sequence repeat GTT are presented in Figure 2. The results revealed that the numbers of repeat units GTT in 
Table 2 Characterisations of EST-SSR marker primer pairs for PCR amplification based on DNA samples of one individual in Casuarina glauca, C. cunninghamiana, C. junghuniana and C. equisetifolia and eight clones of C. equisetifolia

\begin{tabular}{|c|c|c|c|c|}
\hline Locus & Repeat motif & Primer sequences $\left(5^{\prime}-3^{\prime}\right)$ & $\begin{array}{l}\text { Expected product } \\
\text { size (bp) }\end{array}$ & $\begin{array}{c}\text { Annealing } \\
\text { temperature } \\
\left({ }^{\circ}\right)\end{array}$ \\
\hline \multirow{2}{*}{ EST-C01 } & \multirow{2}{*}{$(\mathrm{AGA})_{6}$} & F: TGCAGCATCATCACTACT & \multirow{2}{*}{297} & \multirow{2}{*}{54} \\
\hline & & R: ACTCCAACCAACTCTATTC & & \\
\hline \multirow{2}{*}{ EST-C02 } & \multirow{2}{*}{$(\mathrm{CTTCT})_{5}$} & F: TTTGTCTTCCCTACTCCG & \multirow{2}{*}{162} & \multirow{2}{*}{52} \\
\hline & & R: AACCCTTTTCCACTTTCTTA & & \\
\hline \multirow{2}{*}{ EST-C03 } & \multirow{2}{*}{$(\mathrm{CTT})_{6}$} & F: TTCAAAACCCTAGCATCT & \multirow{2}{*}{200} & \multirow{2}{*}{50} \\
\hline & & R: CATACCATTAACCAAAGC & & \\
\hline \multirow{2}{*}{ EST-C04 } & \multirow{2}{*}{$(\mathrm{CT})_{14}$} & F: GCTGGAGGTGGTGGTGTT & \multirow{2}{*}{256} & \multirow{2}{*}{56} \\
\hline & & R:TATGGAATAGACGAGAAGTGAG & & \\
\hline \multirow{2}{*}{ EST-C05 } & \multirow{2}{*}{$(\text { TCGCAC })_{3}$} & F: CATCTGAACTTTTGAAACCCTA & \multirow{2}{*}{197} & \multirow{2}{*}{56} \\
\hline & & R: GGCATGGCTTCGTCTTGG & & \\
\hline \multirow{2}{*}{ EST-C06 } & \multirow{2}{*}{$(\mathrm{TAG})_{6}$} & F: GCCGAGTTATGGGGACGA & \multirow{2}{*}{240} & \multirow{2}{*}{52} \\
\hline & & R: GGTGTTTGTGACGACGCT & & \\
\hline \multirow{2}{*}{ EST-C07 } & $(\mathrm{CGT})_{6}$ & F: GCACGGTCGTCTTATTCT & 265 & 54 \\
\hline & & R: TCGCTTCCCATACAAATC & & \\
\hline EST-C08 & $(\mathrm{GAC})_{10}$ & F: GCTTTGTCCTACCGTTTC & 148 & 52 \\
\hline & (GAT) 12 & R: ATCACCACCATCGTCGTC & & \\
\hline EST-C09 & $(\mathrm{TCT})_{10}$ & F: CTATTGTTGTGCTTCATCCT & 110 & 57 \\
\hline & (1010 10 & R: CAATAGTCCTAGCACCATT & & \\
\hline EST-C10 & $(\mathrm{GTT})_{9}$ & F: AAAGAGAGGCTCAGAAAGA & 165 & 55 \\
\hline & & R: GCACGAAGCAAGAGATAGA & & \\
\hline EST-C11 & (CAACGACAA) & F: CCTCAAACCAAGACCACC & 320 & 52 \\
\hline & 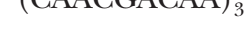 & R: CCGACTTCCATGCTCAAT & 320 & 02 \\
\hline EST-C12 & $(\mathrm{TG})$ & F: TGCCGCTGAACAAAATGA & 946 & 54 \\
\hline 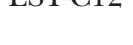 & 11079 & R: ATGGTCTCGCCTGGAATG & $2 \pi 0$ & T \\
\hline EST-C13 & $(\text { CATCTT })_{2}$ & F: ATGGGACATTTTGGTGAT & 989 & 50 \\
\hline & (4) & R: CTTTGCTTTAGGCGTTTT & & \\
\hline EST-C14 & $(\mathrm{TC})_{9}$ & F: CCCTGCTTCTGGTCATTC & 226 & 56 \\
\hline & & R: GATCTGTGGCTTTGCTTG & & \\
\hline EST-C15 & & F: CTTCGCCGTTTCCTCAGA & 195 & 55 \\
\hline (2) & $(\mathrm{HU}) 13$ & R: ATATTTGCTTCGCAGGTCA & & (5) \\
\hline EST-C16 & $(\mathrm{GAA})_{5}$ & F: ATGATGAAGACGAGGATC & 165 & 54 \\
\hline & & R: CTTCTTCTTCTTCСACCAC & & \\
\hline EST-C17 & $(\mathrm{AG})_{17}$ & F: GAATCAAGAACCGCGAAC & 311 & 56 \\
\hline & & R: TCCGAATACCAGACTCCAG & & \\
\hline EST-C18 & $(\mathrm{CT})_{12}$ & F: AAAGGCACAAGTTAGGAGAG & 214 & 56 \\
\hline & & R: GCTGGTGCTGTTGAAATG & & \\
\hline EST-C19 & $(\mathrm{CT})_{7}$ & F: CGACCCAACCAAAATCTC & 260 & 55 \\
\hline & & R: AAGCGACAATCTGAAAGAAG & & \\
\hline FST-C 20 & $(\mathrm{AAGAAC})$ & F: GAAATGCTTATACAGAGAGG & 939 & 56 \\
\hline & 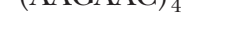 & R: AATCTTCACGATAACTGAGG & & \\
\hline EST-C21 & $(\text { TCTT })_{6}$ & F: AATCTAACAACTGCTTTGGC & 286 & 57 \\
\hline & & R: GGGATGCTGATCGTAACAT & & \\
\hline
\end{tabular}


four clones were 9, 10, 8 and 2 respectively. Both flanking regions of repeat motifs GTT in each clone presented a high degree of uniformity, confirming the high conservation of nonmicrosatellite nucleotide sequences between closely related species (Figure 2).

\section{Paternity analyses of open-pollinated progenies of $C$. equisetifolia}

The first eight SSR primer pairs (EST-C01 to EST-C08) in Table 2 were used to genotype the 461 progeny seedlings originating from one mother tree of C. equisetifolia. In the paternity analyses using CERVUS Version 3.0 (Kalinowski et al. 2007), at $95 \%$ confidence interval, 262 out of 461 progenies were assigned to 76 male individuals as pollen donors. However, at $80 \%$ confidence interval, 328 progenies were assigned to 84 male individuals as father trees. In the remaining 199 and 133 progenies, at 95 and 80\% confidence intervals respectively, the paternity analysis failed to identify their father trees, and this may be due to external pollen flow or missing data at some loci.

Table 3 Allelic profiles of eight clones of C. equisetifolia and four species within Casuarina genus

\begin{tabular}{|c|c|c|c|c|c|c|c|c|c|c|}
\hline SSR locus & EST-C01 & EST-C02 & EST-C03 & EST-C04 & EST-C05 & EST-C06 & EST-C07 & EST-C08 & EST-C09 & EST-C10 \\
\hline individual & $\mathrm{A} 1 / \mathrm{A} 2$ & $\mathrm{~A} 1 / \mathrm{A} 2$ & A1/A2 & $\mathrm{A} 1 / \mathrm{A} 2$ & $\mathrm{~A} 1 / \mathrm{A} 2$ & $\mathrm{~A} 1 / \mathrm{A} 2$ & $\mathrm{~A} 1 / \mathrm{A} 2$ & $\mathrm{~A} 1 / \mathrm{A} 2$ & $\mathrm{~A} 1 / \mathrm{A} 2$ & $\mathrm{~A} 1 / \mathrm{A} 2$ \\
\hline C1 & $297 / 306$ & $148 / 158$ & $217 / 199$ & $240 / 240$ & $197 / 197$ & $244 / 244$ & $264 / 264$ & $144 / 140$ & $110 / 119$ & $165 / 165$ \\
\hline C2 & $294 / 294$ & $158 / 158$ & $217 / 199$ & $240 / 240$ & $197 / 197$ & $235 / 235$ & $264 / 264$ & $144 / 144$ & $125 / 110$ & $165 / 174$ \\
\hline C3 & $297 / 306$ & $148 / 158$ & $217 / 199$ & $240 / 240$ & $185 / 197$ & $244 / 244$ & $252 / 264$ & null & $110 / 110$ & $162 / 165$ \\
\hline $\mathrm{C} 4$ & $297 / 306$ & $158 / 158$ & $220 / 220$ & $240 / 240$ & $197 / 197$ & $244 / 244$ & $260 / 264$ & $144 / 144$ & $110 / 110$ & $162 / 165$ \\
\hline C5 & 294 & 58 & $217 / 217$ & 40 & 97 & $246 / 246$ & 264 & 144 & 10 & 165 \\
\hline C6 & $297 / 306$ & $160 / 160$ & $199 / 217$ & $240 / 240$ & $197 / 197$ & $246 / 246$ & $264 / 264$ & $144 / 144$ & $125 / 125$ & $165 / 165$ \\
\hline C7 & $297 / 306$ & $160 / 160$ & $217 / 217$ & null & $197 / 197$ & $240 / 240$ & $264 / 264$ & $144 / 144$ & $125 / 125$ & $165 / 165$ \\
\hline C8 & $294 / 294$ & $160 / 160$ & $217 / 217$ & $240 / 240$ & $197 / 197$ & $240 / 240$ & $264 / 264$ & $144 / 144$ & $125 / 125$ & $165 / 165$ \\
\hline Sp1 & $297 / 306$ & $158 / 158$ & $217 / 217$ & $242 / 242$ & $185 / 197$ & $242 / 242$ & $264 / 264$ & $136 / 136$ & $119 / 125$ & $159 / 165$ \\
\hline Sp2 & $303 / 303$ & $158 / 158$ & $217 / 199$ & $240 / 256$ & $179 / 179$ & $244 / 244$ & $264 / 264$ & $140 / 140$ & $110 / 119$ & $165 / 165$ \\
\hline Sp3 & $297 / 306$ & $158 / 158$ & $217 / 199$ & $240 / 240$ & $197 / 197$ & $244 / 244$ & $258 / 264$ & $144 / 144$ & $110 / 119$ & $158 / 165$ \\
\hline Sp4 & $297 / 306$ & $158 / 158$ & $217 / 217$ & $242 / 242$ & $197 / 197$ & $244 / 244$ & $240 / 264$ & $128 / 140$ & $110 / 119$ & $165 / 165$ \\
\hline $\begin{array}{l}\text { No. of } \\
\text { allele }\end{array}$ & 4 & 3 & 3 & 3 & 3 & 5 & 5 & 4 & 3 & 5 \\
\hline
\end{tabular}

C1 to C8 represent clones "Zhanjiang3", "Pingtan 2", "A13", "A8-2", "A13", "701", "Hui 76" and "Hui 98" respectively; Sp1 to Sp4 represent individuals of C. equisetifolia, C. glauca, C. cunninghamiana and C. junghuhniana respectively; $\mathrm{A} 1=$ allele $1, \mathrm{~A} 2=$ allele 2

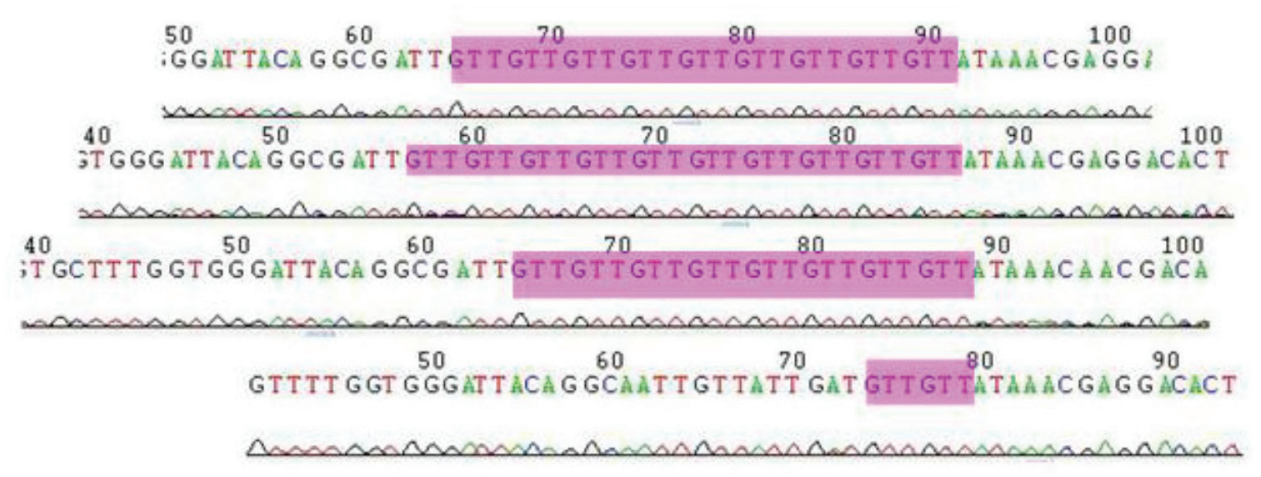

Figure 2 DNA fragment sequences containing variable repeat motifs GTT obtained by amplifying four different cultivars (clones) using primer pair EST-C10 


\section{DISCUSSION}

\section{Frequencies and distribution of SSRs in Casuarina EST sequences}

Owing to the rapid progress in functional genomics research in plants, the number of ESTs in public database is increasing exponentially. Developing SSR markers by means of searching for SSR loci in EST sequences has become a focal point for development of new SSR markers. In this study, a total of 367 SSR loci were identified from 12,063 unigenes of Casuarina indicating that the distribution frequency of SSR loci was only $3.0 \%$. Based on published reports, the abundance of SSRs in ESTs vary widely in different plants. Areshchenkova and Ganal (2002) detected 250 SSR loci from 27,000 EST sequences of tomato, with only $0.93 \%$ distribution frequency. In Liriodendron sp. (Xu et al. 2010) and rubber tree (Hevea brasiliensis) (Feng et al. 2009), relatively higher SSR distribution frequencies with $6.0 \%$ (394 SSRs out of 6520 unigenes) and $12.3 \%$ (1233 SSRs out of 10,018 unigenes) respectively were detected. Furthermore, the average density of one SSR per $19.83 \mathrm{~kb}$ obtained in Casuarina EST sequences was far lower than that of other plants, such as rice $(3.40 \mathrm{~kb})$, maize $(8.10 \mathrm{~kb})$, soybean $(7.40 \mathrm{~kb})$ (Cardle et al. 2000) and barley (6.3 kb) (Thiel et al. 2003), but similar to cotton $(20.00 \mathrm{~kb}$ ) (Cardle et al. 2000). However, the abundance level of SSRs in EST sequences can be influenced by differences in search tools and identification criteria. For example, Rota et al. (2005) found that the frequency of SSRs in rice was reduced from 50 to $1 \%$ when SSR searching parameter of minimum length was changed from 12 to $30 \mathrm{bp}$.

Di- and trinucleotide repeat motifs have been widely reported in plants. The two most common motif types found in Casuarina EST database were di- and trinucleotide repeats, which accounted for $92.4 \%$ of all motif types. Within dinucleotide repeat, AG/CT was the most predominant motif type in Casuarina EST sequences, which was consistent with Arabidopsis (Morgante et al. 2002), rice (Temnykh et al. 2001) and rubber tree (Roy et al. 2004).

\section{Polymorphism and cross-species transferability of SSR markers}

Polymorphism of SSRs originates from the length variations caused by the different number of repeat units. Generally, it was thought that the occurrence of slipped mispairing during DNA replication and repair and unequal crossing-over between repeat units during meiosis accounted for the length variation in SSRs (Strand et al. 1993, Park et al. 2009). In this study, 47 EST-SSR primer pairs either failed to amplify or produced non-specific amplification of SSR products, resulting in exclusion from further polymorphism examination. Causes for amplification failure can be the presence of an intron within the primer sequences that prevents primer annealing, or a large intron in the flanking region that disrupts PCR extension (Cardle et al. 2000, Saha et al. 2004, Park et al. 2009).

Of the remaining 32 primer pairs with successful amplification, 21 produced polymorphic products in the 12 genotypes of Casuarina. All the12 individuals analysed by 10 SSR markers had unique SSR fingerprints (Table 3), validating the high efficiency of these markers in variety discrimination. Furthermore, all the 21 primer pairs presented high cross-species transferability among four Casuarina species in this study. Transferability of microsatellite loci between closely related species is a consequence of homology of flanking regions of simple sequence repeats (Collevatti et al. 1999). ESTSSRs usually demonstrate higher transferability than genomic SSRs due to their relatively more conservative genic regions (Yu et al. 2004). It was reported that 43 of 78 EST-SSR markers exhibited transferability from Triticum to Hordeum (Gupta et al. 2003), but only 2 of 11 SSR markers from an enrichment library of Swietenia humilis showed amplification across the Meliaceae family (White \& Powell 1997). The high cross-species transferability of Casuarina EST-SSR markers make them an excellent tool for parentage analysis of inter-specific hybrids and other genetic studies involving different species of Casuarina.

\section{Application for parentage analysis and retrospective selection of Casuarina}

SSR markers can be used to determine pollen dispersal distance (Broadhurst 2015), mating system (Zhang et al. 2016), and pollen donors (Wei et al. 2015, Ramos et al. 2018) by paternity analysis. In this study, 8 of the 21 newly developed SSR markers were used to determine the father trees of 461 open-pollinated progenies of one female tree. The paternal analysis showed that the 
pollen donors (father trees) of $56.8 \%$ (262 out of 461 ) and $71.1 \%$ (328 out of 461) progenies could be confirmed at 95 and $80 \%$ confidence intervals respectively. Such percentages are similar with results obtained from Pinus massoniana (48.9\%) (Ai et al. 2006), P. tabulaeformis (44.8\%) (Zhang et al. 2009) and Eucalyptus grandis (54\%) (Jones et al. 2008). Failure in identification of paternal parent for the remaining progeny at 95 and $80 \%$ confidence intervals might be attributed to two reasons: (1) there were external pollen sources besides the male trees sampled within the provenance trial to pollinate the female tree selected; and (2) some missing alleles in some loci due to amplification failure or genotyping errors caused paternity analysis failure of some progenies.

Highly informative SSR markers also can be used to develop new breeding strategies for Casuarina by means of retrospective selection. The conventional breeding strategies are to establish progeny trials involving each parent tree, and then evaluate parental contribution to progeny performances by estimating general combining ability (GCA) and specific combining ability (SCA) of the parent trees. However, full-sib progenies of Casuarina obtained from controlled pollination are costly and laborious. An alternative method is to carry out paternity analyses of superior progenies using SSR marker technique in progeny trials established with openpollinated seeds. Parent trees that produce a high frequency of superior offspring mean they possess high GCA and SCA. These hybridogenic parent trees obtained from retrospective selection can be used to establish a new seed orchard for production of superior hybrid seeds.

\section{CONCLUSIONS}

In this study, 21 SSR markers were developed from EST sequences of Casuarina. High polymorphism and cross-species transferability of these SSR markers were confirmed in four species within Casuarina genus and eight clones of C. equisetifolia. Meanwhile, the Mendilian inheritance and co-dominance expression features of SSR marker were verified by means of paternity analysis of open-pollinated progenies of one C. equisetifolia individual. These SSR markers would be efficient tools for further use in parentage analysis, genetic diversity assessment, variety protection, gene mapping and marker-assisted selection of Casuarina tree species in the future.

\section{ACKNOWLEDGEMENTS}

This study was financially supported by the National Natural Science Foundation of China (Grant No. 31770716), and the Fundamental Research Funds for the Central Non-profit Research Institution of CAF (CAFYBB2018ZB003).

\section{REFERENCES}

Ai C, Xu L, Lai HL, Huang MR \& Wang ZR. 2006. Genetic diversity and paternity analysis of a seed orchard in Pinus massoniana. Scientia Silvae Sinicae (in Chinese) 42: 146-151.

Areshchenkova T \& Ganal MW. 2002. Comparative analysis of polymorphism and chromosomal location of tomato microsatellite markers isolated from different sources. Theoretical and Applied Genetics 104: 229-235. doi:10.1007/s00122-001-0775-2

Broadhurst LM. 2011. Genetic diversity and population genetic structure in fragmented Allocasuarina verticillata (Allocasuarinaceae) -implications for restoration. Australian Journal of Botany 59: 770-780. doi: 10.1071/BT11253

Broadhurst LM. 2015. Pollen dispersal in fragmented populations of the dioecious wind-pollinated tree Allocasuarina verticillata (drooping she-oak, Allocasuarinaceae). Plos One 10. doi:10.1371/journal. pone.0119498

Cardle L, Ramsay L, Milbourne D, Macaulay M, Marshall D \& WAUGH R. 2000. Computational and experimental characterization of physically clustered simple sequence repeats in plants. Genetics 156: 847-854. doi: 10.1093/genetics/156.2.847

Collevatti RG, Brondani RV \& Grattapaglia DG. 1999. Development and characterization of microsatellite markers for genetic analysis of a Brazilian endangered tree species Caryocar brasiliense. Heredity 83: 748-756. doi:10.1046/j.1365-2540.1999.00638.x

DoYle JJ \& DoYle JL. 1990. Isolation of plant DNA from fresh tissue. Focus 12: 13-15.

Feng SP, Li WG, Huang HS, Wang JY \& Wu YT. 2009. Development, characterization and cross-species/ genera transferability of EST-SSR markers for rubber tree (Hevea brasiliensis). Molecular Breeding 23: 85-97. doi: 10.1007/s11032-008-9216-0

Gaskin JF, Wheeler GS, Purcell MF \& Taylor GS. 2009. Molecular evidence of hybridization in Florida's sheoak (Casuarina spp.) invasion. Molecular Ecology 18: 3216-3226. doi: 10.1111/j.1365-294X.2009.04282.x

Gupta PK, Rustgi S, Sharma S, Singh R, Kumar N \& Balyan HS. 2003. Transferable EST-SSR markers for the study of polymorphism and genetic diversity in bread wheat. Molecular Genetics and Genomics 270: 315-323. doi: 10.1007/s00438-003-0921-4

Ho KY, Ou CH, Yang JC \& Hsiao JY. 2002. An assessment of DNA polymorphisms and genetic relationships of Casuarina equisetifolia using RAPD markers. Botanical Bulletin of Academia Sinica 43: 93-98.

Ho KY \& LeE SC. 2011. ISSR-based genetic diversity of Casuarina spp. in coastal windbreaks of Taiwan. 
African Journal of Agricultural Research 6: 5664-5671. doi: 10.5897/AJAR10.864

Ho WS, Wickneswari R, Mahani MC \& Shukor MN. 2006. Comparative genetic diversity studies of Shorea curtish (Dipterocarpaceae): an assessment using SSR and DAMD markers. Journal of Tropical Forest Science 18: 22-35.

Hocher V, Auguy F, Argout X, Laplaze L, Franche C \& Bogusz D. 2006. Expressed sequence-tag analysis in Casuarina glauca actinorhizal nodule and root. New Phytologist 169: 681-688. doi: 10.1111/j.14698137.2006.01644.x

Huang GH, Zhong CL, Su XH et al. 2009. Genetic variation and structure of native and introduced Casuarina equisetifolia (L. Johnson) provenances. Silvae Genetica 58: 79-85. doi: 10.1515/sg-2009-0010

Huang GH, Liang KN, Zhou ZZ \& Ma HM. 2016. SSR genotyping-genetic diversity and fingerprinting of teak (Tectona grandis) clones. Journal of Tropical Forest Science 28: 48-58.

Jones ME, Shepherd M, Henry R \& Delves A. 2008. Pollen flow in Eucalyptus grandis determined by paternity analysis using microsatellite markers. Tree Genetics Eं Genomes 4: 37-47. doi: 10.1007/s11295-007-0086-0

Kalinowski ST, Taper ML \& Marshall TC. 2007. Revising how the computer program CERVUS accommodates genotyping error increases success in paternity assignment. Molecular Ecology 16: 1099-1106. doi: 10.1111/j.1365-294X.2007.03089.x

Lee CT, Norlia B, TNah LH et al. 2018. Isolation and characterisation of SSR markers in tongkat ali (Eurycoma longifolia) using next-generation sequencing approach. Journal of Tropical Forest Science 30: 279-291. doi: 10.26525/jtfs2018.30.3.279291

Morgante M, Hanafey M \& Powell W. 2002. Microsatellites are preferentially associated with nonrepetitive DNA in plant genomes. Nature Genetics 30: 194-200. doi: $10.1038 /$ ng822.

Nagarajan B, Nicodemus A, Mandal AK, Verma RK \& Mahadevan NP. 1998. Phenology and controlled pollination studies in tamarind. Silvae Genetica 47: 237-241.

Park YJ, Lee JK \& Kim NS. 2009. Simple sequence repeat polymorphisms (SSRPs) for evaluation of molecular diversity and germplasm classification of minor crops. Molecules 14: 4546-4569. doi: 10.3390/ molecules 14114546

Powell W, Machray GC \& Provan J. 1996. Polymorphism revealed by simple sequence repeats. Trends in Plant Science 1: 215-222. doi: 10.1016/1360-1385(96) 86898-1

Ramos SLF, Dequigiovanni G, Sebbenn AM et al. 2018. Paternity analysis, pollen flow, and spatial genetic structure of a natural population of Euterpe precatoria in the Brazilian Amazon. Ecology and Evolution 8: 11143-11157. doi: 10.1002/ece3.4582

Rota M, Kantety RV, Yu JK \& Sorrells ME. 2005. Nonrandom distribution and frequencies of genomic and EST-derived microsatellite markers in rice, wheat and barley. BMC Genomics 6: 23. doi:10.1186/14712164-6-23

Roy CB, NAzeER MA \& SAHA T. 2004. Identification of simple sequence repeats in rubber (Hevea brasiliensis). Current Science 87: 807-811.
Saha MC, Mian Mar, Eujayl I, Zwonitzer JC, Wang L \& MAY GD. 2004. Tall fescue EST-SSR markers with transferability across several grass species. Theoretical and Applied Genetics 109: 783-791. doi: 10.1007/ s00122-004-1681-1

Samarakoon MB, Tanaka N \& Limura K. 2013. Improvement of effectiveness of existing Casuarina equisetifolia forests in mitigating tsunami damage. Journal of Environmental Management 114: 105-114. doi: 10.1016/j.jenvman.2012.10.050

Strand M, Prolla TA, Liskay RM \& Pets TD. 1993. Destabilization of tracts of simple repetitive DNA in yeast by mutations affecting DNA mismatch repair. Nature 365: 274-276. doi: 10.1038/365274a0

Temnykh S, Declerck G, Lukashova A, Lipovich L, Cartinhour S \& Mccouch S. 2001. Computational and experimental analysis of microsatellites in rice (Oryza sativa $\mathrm{L}$.): frequency, length variation, transposon associations, and genetic marker potential. Genome Research 11: 1441-1452. doi: 10.1101/gr.184001

Thiel T, Michalek W \& VARShNey RK. 2003. Exploiting EST database for the development and characterization of gene derived SSR-markers in barley (Hordeum vulgare L.). Theoretical Applied Genetics 106: 411-422. doi: 10.1007/s00122-002-1031-0

Turnbull JW. 1990. Taxonomy and genetic variation in casuarinas. Pp 1-12 in El-Lakany $\mathrm{MH}$ et al. (eds) Advances in Casuarina Research and Uutilization: Proceedings of the Second International Casuarina Workshop. 15-20 January 1990, Cairo.

WARREN MW \& Zou XM. 2002. Soil macrofauna and litter nutrients in three tropical tree plantations on a disturbed site in Puerto Rico. Forest Ecology and Management 170: 161-171. doi: 10.1016/S03781127(01)00770-8

Wei ZG, Qu ZS, Hou C eT AL. 2015. Genetic diversity and paternal analysis of open-pollinated progenies of Larix olgensis seed orchard. Journal of Nature and Science 19: 1-7.

White G \& Powell W. 1997. Cross-species amplification of SSR loci in the Meliaceae family. Molecular Ecology 6: 1195-1197. doi: 10.1046/j.1365-294X.1997.00297.x

Xu M, Sun YG \& Li HG. 2010. EST-SSRs development and paternity analysis for Liriodendron spp. New Forests 40: 361-382. doi: 10.1007/s11056-010-9205-0

Xu X, Zhou C, Zhang Y et al. 2018. A novel set of 223 EST-SSR markers in Casuarina L. ex Adans.: polymorphisms, cross-species transferability, and utility for commercial clone genotyping. Tree Genetics $\mathcal{E}$ Genomes 14: 30. doi.org/10.1007/s11295-018$1246-0$

Yasodha R, Kathirvel M, Sumathi R, Gurumurthi K, Archak S \& Nagaraju J. 2004. Genetic analyses of casuarinas using ISSR and FISSR markers. Genetica 122: 161-172. doi:10.1023/B:GENE.0000040938.13344.70

Yu JK, Rota ML, Kantety RV \& Sorrells ME. 2004. EST derived SSR markers for comparative mapping in wheat and rice. Molecular Genetics $\mathcal{E}$ Genomics 271: 742-751. doi: 10.1007/s00438-004-1027-3

Zhang DM, Sun PG, Shen XH \& Ru GX. 2009. Paternity analysis of open- and control-pollinated seeds collected from a seed orchard of Pinus tabulaeformis. Journal of Plant Ecology (Chinese Version) 33: 302-310. 
Zhang Y, Zhong CL, Han Q et al. 2014. A novel approach for controlled pollination in Casuarina equisetifolia. Silvae Genetica 263: 76-80. doi: 10.1515/sg-2014-0011

Zhang Y, Zhong CL, Han Q et al. 2016. Reproductive biology and breeding system in Casuarina equisetifolia (Casuarinaceae)-implication for genetic improvement. Australian Journal of Botany 64: 120 128. doi: 10.1071/BT15184
Zhong CL, Zhang Y, Chen Yet al. 2011. Casuarina research and development in China. Pp 5-10 in Zhong CL et al. (eds) Improving Smallholder Livelihoods Through Improved Casuarina Productivity: Proceedings of the 4th International Casuarinas Workshop. 21-25 March 2010, Haikou. 